ACTA UNIVERSITATIS LODZIENSIS

FOLIA LITTERARIA POLONICA 1(39) 2017

http://dx.doi.org/10.18778/1505-9057.39.06

Małgorzata Kita*

\title{
Radio i oralność - z perspektywy językoznawczej
}

\section{Wprowadzenie}

Pod koniec XIX wieku [wieku pary, wieku techniki] człowiekowi zaczęło towarzyszyć radio - i jest z nim nadal. Nowy wynalazek techniczny szybko został medium komunikacji masowej, stał się codziennym ,gadżetem” popkulturowym"

Dla większości słuchaczy podstawowe funkcje radia: dźwiękowej tapety [accoustic wallpaper], zegara, dostarczyciela w określonych porach dnia [głównie rano i przed popołudniem] podstawowych informacji, prognozy pogody, połączone z wyborem ulubionych formatów muzycznych stanowią wystarczające powody, by włączać radioodbiorniki lub w inny sposób percypować przekaz radiowy².

Dzięki połączeniu telegrafu Samuela F. Morse’a, telefonu Aleksandra G. Bella, fonografu Thomasa A. Edisona i teorii fal elektromagnetycznych Jamesa C. Maxwella powstało coś, co spełniło ludzkie marzenie o dźwięku przesyłanym na odległość. Radio, zachowując swoją istotę, ewoluuje wraz ze zmianami technologicznymi:

Rozwój telefonii umożliwił kontakt ze słuchaczem na antenie i konstruowanie form i gatunków uwzględniających ten aspekt komunikacji [np. call-ins, interaktywna audycja publicystyczna, phone-out, game show], zastosowanie tranzystorów zapoczątkowało mobilność radia i wpłynęło na kształt ramówek uwzględniających odtąd serwisy drogowe, integrowanie transmisji radiowej z pracą centrów monitoringu

* Prof. dr hab., e-mail: malgorzatka.kita@gmail.com; Uniwersytet Śląski w Katowicach, Wydział Filologiczny, Katedra Międzynarodowych Studiów Polskich; 40-032 Katowice, Pl. Sejmu Śląskiego 1.

${ }^{1} \mathrm{~W}$ rozumieniu autorów monografii zbiorowej Gadżety popkultury. Społeczne życie przedmiotów, red. W. Godzic, M. Żakowski, Wydawnictwa Naukowe i Profesjonalne, Warszawa 2007.

${ }^{2}$ B. Skowronek, Mediolingwistyka. Wprowadzenie, Wydawnictwo Naukowe Uniwersytetu Pedagogicznego, Kraków 2013, s. 211. 
ruchu, szczególnie w dużych aglomeracjach miejskich, odwoływanie się do pozadomowej aktywności słuchaczy [audycje towarzyszące], techniki przetwarzania dźwięku pozwoliły nagrywać i wielokrotnie odtwarzać słuchowiska [początkowo rejestrowane jako ogromne przedsięwzięcia plenerowe rozgrywające się jedynie na żywo], wykorzystywać materiały archiwalne i komponować je w fingowane dialogi [talk-joke], natomiast skonwergowanie radia z telewizją, a zwłaszcza z Internetem dało impuls do rozwoju form konglomeratowych komunikacji, w których kanał audialny jest uzupełniany obrazem, tekstem czy filmem [podcasty, hang-outy, fotocasty] $]^{3}$.

Dodajmy: obecnie dostrzega się zmianę kodów semiotycznych radia, co wiąże się z cyfryzacją mediów i procesami konwergencyjnymi" ,Z przyszłością radia łączy się nie tylko dźwięk, ale również obraz, grafikę, tekst, przekaz danych"5.

Radio wynalazł Guglielmo Marconi, za datę powstania radia uznaje się rok 1901, kiedy to udało mu się przesłać sygnał radiowy przez Atlantyk ${ }^{6}$. Potencjał wynalazku wykorzystała bezzwłocznie marynarka wojenna, by przesyłać informacje za pośrednictwem radia. Dopiero później odbiornik radiowy ,zbłądził pod strzechy" i to dosłownie, zmieniając, czy właściwie rewolucjonizując świat mediów, demokratyzując czy deelitaryzując dostęp do informacji. Już bowiem nie tylko elita intelektualna i finansowa mogła korzystać z nowego medium, ale także ludzie o niskim wykształceniu i niskim statusie materialnym zyskali dostęp do informacji, dotychczas dostarczanej przez prasę - płatną i wymagającą umiejętności czytania, a ta ostatnia nie należała do kompetencji powszechnie

${ }^{3}$ G. Stachyra, Radiomorfozy. Profilowanie przekazu na przykladzie radia Hair Trendy, [w:] Radio w dobie nowych mediów, red. U. Doliwa, Wydawnictwo Uniwersytetu Warmińsko-Mazurskiego, Olsztyn 2014, s. 115-116.

${ }^{4}$ Przekraczanie granic medium dźwięku widoczne jest np. w realizacji przez Polskie Radio Czwórka projektu „Radio na wizji” ze sloganem Radio/Czwórka z wizją. Polega on na jednoczesnym emitowaniu tej samej audycji w wersji audialnej [jako program radiowy] i wersji audiowizualnej [jako program telewizyjny]. Emisję testową Radia na Wizji uruchomiono 17 grudnia 2010 r. Oficjalny, regularny przekaz Radia na Wizji rozpoczęto w dniu 18 stycznia 2011 r. o godzinie 23:00 [zob. hasło: Polskie Radio Program IV, https://pl.wikipedia.org/wiki/Polskie_Radio_Program_IV [dostęp: 26.06.2016]. Przejawem mariażu radia i telewizji jest też piątkowa rozmowa $\overline{\mathrm{w}} 2012 \mathrm{r}$. $\overline{\mathrm{w}}$ porannym paśmie „Zapraszamy do Trójki” prowadzona przez Wojciecha Manna i Michała Nogasia [z cyklu „Trójkowy Znak Jakości”], dotycząca książek rekomendowanych przez dziennikarzy, której część była także transmitowana w TVP 1 w paśmie „Kawa czy herbata?”. O zmianach w radiu zob. Radio i społeczeństwo, red. G. Stachyra, E. Pawlak-Hejno, Wydawnictwo Uniwersytetu Marii Curie-Skłodowskiej, Lublin 2011.

${ }^{5}$ S. Jędrzejewski, Radio. Narodziny - ewolucja - perspektywy, [w:] Dziennikarstwo i świat mediów. Nowa edycja, red. Z. Bauer, E. Chudziński, Towarzystwo Autorów i Wydawców Prac Naukowych Universitas, Kraków 2010, s. 126.

${ }^{6}$ Zob. A. Briggs, P. Burke, Spoteczna historia mediów: od Gutenberga do Internetu, przekł. J. Jedliński, Wydawnictwo Naukowe PWN, Warszawa 2010. 
posiadanych: „W odróżnieniu od prasy radio «unieważnia» wykształcenie, ponieważ w przeciwieństwie do prasy nie wymaga umiejętności czytania"’

Politycy z rozmachem włączyli radio w służbę ideologii. Przykładem może być hitlerowska Trzecia Rzesza, odważnie modernizująca kraj, czego widoczne przejawy stanowią: autostrady, samoloty, samochody VW, radio . Już w 1933 roku, po dojściu Hitlera do władzy, Goebbels stworzył imperium medialne, które posługiwało się radiem jako instrumentem służącym przekazywaniu przez władzę ideologii nazistowskiej społeczeństwu. W państwie totalitarnym radio stało się wszechobecne: $\mathrm{w}$ radioodbiorniki były wyposażone nie tylko domy i mieszkania zwykłych Niemców, ale również zakłady pracy, restauracje i kawiarnie, a na ulicach miast pojawiły się maszty z megafonami. Każdy i wszędzie mógł słuchać radia, a w nim m.in. przemówień führera. W 1933 roku w Niemczech było 4,5 miliona radioodbiorników, w 1939 roku - 12 milionów, a w 1942 roku - 16 milionów. W 1939 roku co drugie niemieckie gospodarstwo domowe miało radio ${ }^{10}$.

Wynalezione na przełomie wieków XIX i XX i nazywane początkowo „telegrafem bez drutu" radio w Polsce zaczęło nadawać 1 lutego 1925 roku $^{11}$. Polskie Radio $^{12}$ stało się jedną z najważniejszych instytucji odrodzonej Polski, zyskało też ważną rolę w językowej - i nie tylko językowej - edukacji Polaków ${ }^{13}$.

\section{Radio - medium jednego zmysłu}

Czym jest radio? Nie chodzi tu o definicję specjalistyczną ${ }^{14}$, lecz o to, jak radio postrzegane jest przez racjonalność potoczną, co przychodzi na myśl „,zwykłemu człowiekowi”, kiedy styka się ze słowem „radio”. Inny słownik języka

${ }^{7}$ S. Jędrzejewski, Radio, [w:] Stownik wiedzy o mediach, red. E. Chudziński, Wydawnictwo Szkolne PWN, Warszawa, ParkEdukacja Bielsko-Biała 2007, s. 155.

${ }^{8}$ http://alehistoria.blox.pl/2012/05/BRUNATNE-CZASY-RADIA.html [dostęp: 26.06.2016].

${ }^{9} \mathrm{http}: / /$ www.tygodnikprzeglad.pl/radiowe-imperium-goebbelsa/ [dostęp: 26.06.2016].

${ }^{10}$ R. Moorhouse, Stolica Hitlera. Życie i śmierć w wojennym Berlinie, przekł. J. Wąsiński, Społeczny Instytut Wydawniczy Znak, Kraków 2011.

${ }^{11} \mathrm{~W}$ innych krajach radiostacje zaczęły funkcjonować wcześniej. Pierwszeństwo w tym zakresie przypada Amerykanom - stało się to w roku 1920. Dwa lata później pierwsze audycje usłyszeli mieszkańcy ZSRR, Francji oraz Wielkiej Brytanii. W Niemczech i Czechosłowacji początek emisji radiowej przypada na rok 1923.

${ }^{12} \mathrm{~W}$ sierpniu $1925 \mathrm{r}$. koncesję na nadawanie programu ogólnopolskiego przez 20 lat otrzymała spółka Polskie Radio SA. O historii radia w Polsce zob. M.J. Kwiatkowski, Narodziny Polskiego Radia: radiofonia w Polsce w latach 1918-1929, Państwowe Wydawnictwo Naukowe, Warszawa 1972.

${ }^{13}$ Zob. I. Bajerowa, Język ogólnopolski XX w., [w:] Wspótczesny język polski, red. J. Bartmiński, Wydawnictwo Uniwersytetu Marii Curie-Skłodowskiej, Lublin 2001.

${ }^{14}$ Tę znajdziemy w publikacjach naukowych z zakresu radioznawstwa i szerzej: medioznawstwa. 
polskiego $P W N$, który z założenia stara się oddawać w artykułach hasłowych wiedzę potoczną przeciętnego użytkownika języka, definiuje je jako „1. urządzenie służące do odbioru programów dźwiękowych nadawanych w postaci fal elektromagnetycznych przez specjalne stacje nadawcze"15. Sam użytkownik, mający je zdefiniować, mówi: ,to taki przyrząd z guziczkiem. Jak się ten guziczek wciśnie, słychać głosy. Chodzi o to, żeby te głosy, żeby te opowieści były ciekawe, barwne, różnorodne. Ludzkie"16. Poeta jest zaś nieco złośliwy, kiedy przewrotnie charakteryzuje radio: „Radio to cudowny wynalazek! Jeden ruch ręki - i nic nie słychać", powiada Julian Tuwim ${ }^{17}$.

Jak widać, jest ono postrzegane jako medium jednego zmysłu - zmysłu dźwięku. Także dźwięku językowego; co ważne: „Radio odrodziło znaczenie mówcy i słowa, dając możliwość przemówienia do człowieka głosem, który zdawało się, że stracił już swój walor dla informacji i propagandy"18.

Uznaje się je za medium „gorące” - zgodnie z podziałem McLuhanowskim $^{19}$ - czyli takie, które przedłuża pojedynczy zmysł odbiorcy z wysoką rozdzielczością, co oznacza, że zaspokaja całość jego potrzeb i nie wymaga od niego aktywnego uzupełnienia przekazu. Przekaz gorący [poza radiem także fotografia, film, druk] mniej angażuje odbiorcę niż media zimne: telewizja, telefon, mowa, wywołuje też silne, choć krótkotrwałe doświadczenia, emocje. Siły oddziaływania radia dowodzi paniczna reakcja prawie miliona Amerykanów na słuchowisko Orsona Wellesa [1938] o inwazji Marsjan na Stany Zjednoczone [adaptacja Wojny światów Herberta George’a Wellsa ${ }^{20}$ ] potraktowanego jako reportaż o rzeczywistych wydarzeniach ${ }^{21}$. I nie wydaje się istotne to, że wydarzenie to miało miejsce $\mathrm{w}$ epoce, kiedy radio było jeszcze relatywnie nowym medium i nie wykształciły się, być może, kompetencje medialne pozwalające dostrzegać specyfikę medium i interpretować genologiczną naturę komunikatu.

${ }^{15}$ Inny słownik języka polskiego PWN, t. 2, red. M. Bańko, Wydawnictwo Naukowe PWN, Warszawa 2000.

${ }^{16} \mathrm{http} / / /$ www.polskieradio.pl/9/398/Artykul/231470,Co-to-jest-radio [dostęp: 26.06.2016].

${ }^{17} \mathrm{https} / / /$ pl.wikiquote.org/wiki/Radio [dostęp: 26.06.2016].

${ }^{18}$ H. Jabłoński, Opinia, parlament, prasa. Wstęp do badań roli opinii publicznej w epoce rozkwitu kapitalizmu, Zakład Narodowy im. Ossolińskich, Wrocław 1985, s. 275.

${ }^{19}$ M. McLuhan, Wybór pism, przekł. K. Jakubowicz, Wydawnictwa Artystyczne i Filmowe, Warszawa 1975, zob. też tenże, Zrozumieć media. Przedlużenia człowieka, przekł. N. Szczucka, Wydawnictwa Naukowo-Techniczne, Warszawa 2004.

${ }^{20}$ Zob. https://www.youtube.com/watch?v=Xs0K4ApW14g [dostęp: 26.06.2016].

${ }^{21}$ Zob. http://www.polskieradio.pl/39/156/Artyku1/713951,Wojna-swiatow-tylko-Clint-Eastwood -nie-uwierzyl-w-te-historie [dostęp: 26.06.2016]. 


\section{Pejzaż dźwiękowy czlowieka}

Słowo mówione było ważne już u początków kultury ludzkiej: kultury pierwotne były par excellence oralne. Stanowi ono jeden z elementów ludzkiej audiosfery. Jej właściwością jest dwuwektorowość. $Z$ jednej strony człowiek bez patologii / dysfunkcji zmysłu słuchu permanentnie doświadcza życia w świecie dźwięku: dźwięku natury, dźwięku generowanego przez technikę, przez artefakty ludzkie, z drugiej strony nieustannie też emituje dźwięki ze swojego wnętrza: artykułowane i nieartykułowane dźwięki językowo-komunikacyjne oraz dźwięki niezależne od woli człowieka, a związane z jego naturą biologiczną / organiczną: np. oddech, bicie serca, skrzypienie stawów, zgrzytanie zębami, „kiszki grające marsza” itd. Nie jest możliwe, by się od dźwięku uwolnić: można zamknąć oczy i nie widzieć otaczającego świata, podobnie jak w ciemności, ale zasłonięcie uszu nie będzie już tak efektywne, bo będą wówczas percypowane np. odgłosy własnego organizmu. Dźwięki zatem to nieodłączny towarzysz ludzkiej egzystencji:

Pewnego razu wędrował przez świat dźwięk.

Spotkał pod ukwieconym drzewem człowieka.

Wpadł na niego. Zachwycił go.

Przemienił na chwilkę. I popłynął dalej.

Człowiek zachwycony usiadł na chwilę na ławce.

Potem zapomniał o dźwięku i poszedł.

A dźwięk wędrował dalej.

Dni, miesiące, lata, po całym świecie.

I znów spotkał człowieka.

Był w drodze do pracy, gdy dźwięk wpadł na niego

przy szemrzącym strumyku. Przemienił go i pofrunął dalej.

Człowiek, aż przystanął ze zdziwienia. Pomedytował chwilkę,

zapomniał i poszedł dalej.

I tak wędrują, każdy swoją drogą.

Dźwięk i Człowiek.

Gdy się spotykają.

Jeden przemienia drugiego.

Ty jesteś tym człowiekiem.

Tak.

To Ty czasem siadasz na ławce i słuchasz radosnych ptaków, siedzących na kwitnących gałązkach drzew.

To Ty zachwycasz się szumem przepływającej wody. 
Dziwne, że tak rzadko to słyszysz.

Bo dźwięk jest tu zawsze.

Dla Ciebie.

By Cię przemieniać.

Wędruje przez świat cały, by Cię spotkać.

Zechciej i Ty.

Daj się mu przemieniać.

Świat jest wtedy piękniejszy.

Bo dźwięk jest Pięknym darem.

Szczególnie dla Ciebie.

On potrafi Cię otworzyć.

Potrafi Cię przemienić.

Potrzebujesz go, by cieszyć się Życiem.

Wsłuchaj się w niego.

On nieustannie z Tobą wędruje.

Wszędzie.

Jest jak Przyjaciel.

Słuchaj go, bo dobrze ,gada"22.

Radio jest integralnym składnikiem audiosfery. Wszechobecne dźwięki kształtują i formatują człowieka, ale też człowiek, generując dźwięki już samą swą egzystencją, zmienia środowisko akustyczne. Ludzkie doświadczanie audytywne i wizualne dzisiejszego świata tak ujmuje Marian Bugajski:

Współczesna kultura ma zarówno charakter ikoniczny, jak i dźwiękowy w większym stopniu niż w całych dziejach ludzkości, co wiąże się głównie z rozwojem środków technicznych, mających z kolei najważniejszy wpływ na rozwój mass mediów. Otoczeni, a może nawet osaczeni jesteśmy przez obrazy oraz dźwięki i nie ulega wątpliwości, że muszą one na nas oddziaływać. Są wszechobecne i coraz bardziej agresywne. Przestrzeń publiczna w sensie dosłownym i przenośnym jest zaśmiecona obrazami, które nader często trwają tak długo, jak ich materialne podłoże, i dźwiękami, które na szczęście są ograniczone długością i czasem trwania fali dźwiękowej²3.

${ }^{22}$ 12.04.2015, Waldi Saren,Dźwięk, http://waldisaren.bloog.pl/id,347610641,title,Dzwiek,index. html?smoybbtticaid=616e40 [dostęp: 26.06.2016].

${ }^{23}$ M. Bugajski, Język a przestrzenie wizualne i akustyczne, [w:] A. Janiak, W. Krzemińska, A. Wojtasik-Tokarz, Przestrzenie wizualne i akustyczne człowieka. Antropologia audiowizualna jako przedmiot i metoda badań, Wydawnictwo Naukowe Dolnośląskiej Szkoły Wyższej Edukacji TWP, Wrocław 2007, s. 304. 
Antropologia dźwięku, badająca relacje człowieka ze środowiskiem akustycznym, powstała w obrębie antropologii kulturowej, proponuje następującą kategoryzację dźwięków w otoczeniu ludzkim:

1. Fonosfera - dźwięki, które są wynikiem ekspresji głosowej człowieka [np. kaszel, szept, śmiech, oddychanie, dźwięki wypowiadane], ale także te utrwalone za pomocą urządzeń rejestrujących;

2. Sonosfera - zwraca uwagę zarówno na brzmienie, jak i pochodzenie dźwięku, poszukuje wartości w dźwiękach wydawanych nie tylko przez instrumenty [np. szum wodospadu, warkot silnika itd.], inaczej: otaczająca nas dźwiękowa rzeczywistość;

3. Audiosfera-dźwięki i odgłosy stanowiące o specyfice danej przestrzeni ${ }^{24}$.

Człowiek, egzystując w świecie dźwiękowym, doświadcza w kontakcie z dźwiękami przyjemności [śpiew ptaków, fale morza, muzyka], grozy [burza], dyskomfortu [ustawiczny, wzmożony hałas, ale też np. dźwięk paznokcia ślizgającego się po szybie], zostaje ostrzeżony [klakson]. Dźwięki przekazują mu więc informację, także zakodowaną, np. afrykańskie tam-tamy. Kiedy wejdzie w świat bez dźwięków, czuje się zagubiony. Przeżyje go w warunkach ziemskich w komorze bezodbiciowej, potocznie zwanej bezechową ${ }^{25}$, czyli w izolowanym od otoczenia pomieszczeniu, którego ściany wewnętrzne nie odbijają fal dźwiękowych. Komora bezechowa w krakowskiej AGH jest jednym z najcichszych miejsc w Polsce ${ }^{26}$. Poziom ciśnienia akustycznego tła zmierzonego w niej w ciągu dnia

${ }^{24}$ T. Misiak, Estetyczne konteksty audiosfery, Wyższa Szkoła Nauk Humanistycznych i Dziennikarstwa, Poznań 2009. Zob. też R. Losiak, Muzyka w przestrzeni publicznej miasta. Z badań nad pejzażem dźwiękowym Wrocławia, [w:] Dźwięk jako przedmiot badań interdyscyplinarnych. Prace Komisji Krajobrazu Kulturowego, t. 11, red. S. Bernat, Instytut Nauk o Ziemi Uniwersytet Marii Curie-Skłodowskiej, Komisja Krajobrazu Kulturowego Polskiego Towarzystwa Geograficznego, Lublin 2008, s. 253.

25 „Komora bezechowa [ang. anechoic chamber] to pomieszczenie skonstruowane specjalnie do pomiarów akustycznych, tak aby symulować warunki pola swobodnego. W tym celu wszystkie ściany komory bezechowej pokryte są materiałami pochłaniającymi. Materiały pochłaniające w komorach bezechowych zwykle mają postać ostrych, długich klinów wykonanych z wełny mineralnej, waty szklanej lub pianki akustycznej. Najczęściej spotyka się kliny w kształcie, który opracował Leo Beranek na Harvardzie w latach 40. Ponieważ ustroje pochłaniające muszą pokrywać także podłogę pomieszczenia, to zazwyczaj w komorze bezechowej rozciągnięta jest siatka, po której można się wewnątrz poruszać. Oprócz wysokiego pochłaniania dźwięku przez ściany, drugim kluczowym wymaganiem jest wysoka izolacyjność komory, aby dźwięki z zewnątrz nie zakłócały pomiarów", http://www.hifi.pl/slownik/komora-bezechowa.php [dostęp: 26.06.2016].

${ }^{26}$ Istniejąca w Polsce w AGH komora jest ,żelbetowym sześcianem o krawędzi zewnętrznej około $10 \mathrm{~m}$ [objętość około $1000 \mathrm{~m}^{3}$ ]. Objętość użyteczna [pomiędzy klinami] to około $342 \mathrm{~m}^{3}$ [6,7 m x 7,1 m oraz 7,2 m wysokość]. Masa komory jest szacowana na 500 ton, a sama «kostka» jest posadowiona na wibroizolacji wspartej na 50 sprężynach, które ograniczają przenoszenie ewentualnych drgań z budynku i drogi. Ze względu na umieszczenie klinów także na podłodze w komorze można poruszać się po siatce rozciągniętej pół metra nad klinami”, http://www.lat.agh. edu.pl/pomieszczenia/komora-bezechowa/ [dostęp: 26.06.2016]. 
wynosi około 1,5 decybela - dla porównania średni hałas w przeciętnym biurze to około $60 \mathrm{~dB}(\mathrm{~A})$, na ulicy około $90 \mathrm{~dB}(\mathrm{~A})$, a w oddzielonej grubymi murami sypialni około 20 decybeli ${ }^{27}$.

Marzenie o ciszy, które wyrażamy w stanie zmęczenia, gdyby miało być zrealizowane dosłownie, w takiej komorze - przez absolutny brak bodźców akustycznych - wywoła wrażenie dyskomfortu. W nieziemskich i akulturowych warunkach słuch się wytęża, na tyle, że człowiek zaczyna słyszeć bicie swojego serca, a nawet odgłosy z płuc i żołądka, które dość szybko odbierane są przez narząd słuchu jako bardzo głośne dźwięki. Można w niej wytrzymać bez szkody dla kondycji psychicznej kilkadziesiąt minut ${ }^{28}$.

Ideę miejsca absolutnie cichego zrealizował też jako projekt artystyczny Olafur Eliasson. Jest to winda w paryskim Espace culturel Louis Vuitton. Duński artysta stworzył przestrzeń asensorialną, pomieszczenie „zmysłowej entropii”, w którym podróżujący nią człowiek pogrąża się na czas czterdziestosekundowej podróży w absolutnej ciemności i absolutnej ciszy:

Zmysły mają się na moment wyłączyć, człowiek wyciszyć, by przygotować się do kontaktu ze sztuką. Poza tą klatką zmysły atakują obrazy, dźwięki, zapachy... Cisza, brak dźwięków w świecie współczesnym jest dobrem, a właściwie przywilejem i luksusem, dostępnym wybranym ${ }^{29}$.

Dialektycznym dopełnieniem audiosfery jest więc galenosfera, czyli środowisko ciszy. W radiu - medium dźwiękowym - cisza, czyli brak dźwięku ${ }^{30}$, pojawia się na prawach wyjątku: po śmierci wynalazcy radia, Guglielmo Marconiego, uczczono jego pamięć minutą ciszy w eterze ${ }^{31}$. Elżbieta Pleszkun-Olejniczakowa łączy te dwie sfery:

[...] znakiem na antenie jest tyleż słowo dziennikarza, twórcy, co wszelki przekaz niewerbalny, a więc np. dźwięki naturalne czy sztuczne - tu także muzyka, agogika i inne cechy właściwe interpretacji czy w końcu po prostu sama cisza; tyle że w przypadku dzieł audialnych trzeba ją dawkować znacznie rozważniej niż można to

${ }^{27} \mathrm{http}: / /$ naukawpolsce.pap.pl/aktualnosci/news,398768,komora-bezechowa-agh-jak-nowa. html [dostęp: 26.06.2016].

${ }^{28} \mathrm{http}$ //tech.wp.pl/kat,1009779,title,Upiorna-komora-ktora-doprowadza-do-szalenstwa-Ile-bys-wytrzymal,wid,14391366,wiadomosc.html?ticaid=116f18 [dostęp: 26.06.2016].

${ }^{29}$ M. Kita Dyskurs radiowy, [w:] Style wspótczesnej polszczyzny. Przewodnik po stylistyce polskiej, red. E. Malinowska, J. Nocoń, U. Żydek-Bednarczuk, Towarzystwo Autorów i Wydawców Prac Naukowych Universitas, Kraków 2013.

${ }^{30}$ „stan, w którym nie rozlegają się żadne dźwięki”, http://sjp.pwn.pl/sjp/cisza;2449472.html [dostęp: 26.06.2016].

${ }^{31} \mathrm{http}: / /$ www.polskieradio.pl/39/156/Artykul/1085552,Guglielmo-Marconi-i-poczatki-radia [dostęp: 26.06.2016]. 
uczynić w tekstach audiowizualnych, odbiór radiowy ma bowiem tę cechę, że nieco dłuższą ciszę słuchacz może pomylić z... awarią odbiornika ${ }^{32}$.

Godzi się przypomnieć, że ciszy nie można utożsamiać z milczeniem ${ }^{33}$. Do milczenia, czyli braku mówienia [z wyboru, a nie konieczności wywołanej dysfunkcją aparatu fonicznego], zdolny jest homo loquens ${ }^{34}$, cisza jest natomiast atrybutem natury. Miejscem, gdzie istnieje prawdziwa, wszechogarniająca cisza, jest kosmos, czyli przestrzeń nie-ludzka, a właściwie pozaludzka. Dobrze to ilustruje film „Interstellar” w reżyserii Christophera Nolana [światowa premiera odbyła się 6 listopada 2014 roku, a polska 7 listopada 2014 roku], gdzie bardzo dojmujące są kontrasty między ludzkimi emocjami wyrażanymi głosem i mechanicznym hałasem wewnątrz statku kosmicznego a idealną ciszą na zewnątrz, w przestrzeni kosmicznej ${ }^{35}$.

\section{Oralność kultury pierwotnej i koncepcja oralności wtórnej}

Homo loquens, czyli człowiek mówiący, narodził się około 100 tysięcy lat temu, we wschodniej Afryce ${ }^{36}$. Homo scribens, czyli człowiek piszący, jest znacznie młodszy, pismo powstało bowiem kilka tysięcy lat temu ${ }^{37}$. W antropo-

${ }^{32}$ E. Pleszkun-Olejniczakowa, Jak jest zrobione stuchowisko? O morfologii i znaczeniu, o kreacji i znaku, [w:] E. Pleszkun-Olejniczakowa, J. Bachura, A. Pawlik, Dwa teatry. Studia z zakresu teorii i interpretacji sztuki stuchowiskowej, Wydawnictwo Adam Marszałek, Toruń 2011, s. 75.

${ }^{33} \mathrm{O}$ komunikacyjnych aspektach milczenia zob. m.in. Semantyka milczenia: zbiór studiów, red. K. Handke, Instytut Slawistyki Polskiej Akademii Nauk, Katedra Teorii Muzyki Akademii Muzycznej im. Fryderyka Chopina, Slawistyczny Ośrodek Wydawniczy przy Instytucie Slawistyki PAN, Warszawa 1999 oraz Cisza i milczenie. Społeczno-kulturowe mechanizmy kreowania emocji, red. B. Syroka, K. Marcehl, seria Antropologia Emocji, t. 1, Oficyna Wydawnicza Arboretum, Wrocław 2010. Badania nad milczeniem zapoczątkowała Jolanta Rokoszowa, zob. m.in. J. Rokoszowa, Język, czas, milczenie, Wydawnictwo Oddziału Polskiej Akademii Nauk, Warszawa 1999.

${ }^{34}$ Człowiek to nie tylko homo sapiens, gatunek biologiczny o niepowtarzalnych cechach genetycznych, ale także homo creator - twórca cywilizacji oraz animal sociale - czyli twórca złożonych struktur społecznych opartych na współpracy i pomocy wzajemnej. Wreszcie człowiek to homo loquens - istota posługująca się językiem, co umożliwia porozumiewanie się, a także kumulowanie wiedzy i doświadczeń. Zob. też D. Fry, Homo Loquens: Man as a Talking Animal, Cambridge University Press, Cambridge 1977.

${ }^{35}$ Zob. też film Grawitacja w reżyserii Alfonso Cuaróna [2013]. W pierwszym zwiastunie filmu wybuchom towarzyszą efekty dźwiękowe, jednak w ostatecznej wersji filmu spektakularne sceny katastrof w próżni dzieją się w ciszy.

${ }^{36}$ J. Aitchison, Przedmowa, [w:] Atlas języków. Pochodzenie i rozwój języków świata, red. B. Comrie, S. Matthews, M. Polinsky, przekł. P. Gąsiorowski, Oficyna Wydawnicza Atena, Poznań 1998.

${ }^{37} \mathrm{https} / / /$ horyzonty.ignatianum.edu.pl/index.php/HW/article/view/314/281 [dostęp: 26.06.2016]. 
logii mówi się o tzw. wielkim podziale na kultury tradycyjne, oparte na żywym słowie, i kultury pisma, w których żywe słowo straciło wiele ze swoich funkcji. Pismo to wynalazek rewolucyjny: zmieniło tryb komunikacji, utrwalając słowa w czasie i przestrzeni, dokonało także rewolucji w kulturze:

Pismo tworzy zupełnie nowy świat, nowy świat relacji społecznych, nowe instytucje, nowy świat myśli i kategorii myślenia. Pismo zmusza do tego, by formułować myśli niezależnie od kontekstu, by uogólniać - mówił Grzegorz Godlewski. - W komunikacji ustnej słowo nigdy nie jest samo, zawsze współpracuje z naszym ciałem, z naszym głosem, jego barwą, tempem, intencją, z jaką się mówi. To wszystko zanika w piśmie. Wraz z jego pojawieniem się cały świat oralnego doświadczania rzeczywistości trochę się skurczył, został odsunięty na margines. Z pewnością jednak nie zanikł. Wciąż ze sobą rozmawiamy, prowadzimy wykłady i opowiadamy ${ }^{38}$.

Badaczem, który w centrum zainteresowania badawczego postawił oralność kultury, jest Walter Jackson Ong [1912-2003] $]^{39}$, amerykański profesor literatury angielskiej, historyk religii i filozof. Jego dzieło, które budzi wielkie zainteresowanie na całym świecie i daje inspiracje do badań w różnych dyscyplinach zajmujących się kulturą ludzką, to Orality and Literacy. The Technologizing of the Word [1982], przetłumaczone na kilkanaście języków, na polski przełożone przez Józefa Japolę w 1992 roku jako Oralność i piśmienność. Stowo poddane technologii. Polska recepcja myśli Ongowskiej ${ }^{40}$ ma znaczący impakt, generując liczne prace naukowe.

Ujmując oralność jako klucz interpretacyjny kultury ludzkiej ${ }^{41}$, pierwotnej, jak i współczesnej, Ong wskazuje na dwa jej typy: oralność pierwotną, właściwą osobom całkowicie nieobeznanym z pismem, oraz oralność wtórną, właściwą

${ }^{38} \mathrm{http}: / /$ www.polskieradio.pl/8/2222/Artykul/988121,Kultura-oralna-\%E2\%80\%93-slowo-zwiazane-z-cialem [dostęp: 26.06.2016].

${ }^{39}$ Biografia W. Onga znajduje się na http://www.bu.kul.pl/walter-j-ong-jr-sj-1912-2003-sylwetka-i-publikacje,art_11256.html [dostęp: 26.06.2016]. Zob. też http://www.media-ecology.org/ publications/MEA_proceedings/v6/berg.pdf [dostęp: 26.06.2016] oraz J. Japola, Tekst czy głos? Waltera J. Onga antropologia literatury, Redakcja Wydawnictw Katolickiego Uniwersytetu Lubelskiego, Lublin 1998 oraz S. Obirek, Uskrzydlony umyst. Antropologia stowa Waltera Onga, Wydawnictwa Uniwersytetu Warszawskiego, Warszawa 2010.

${ }^{40}$ Perspektywę lingwistyczną przyjmuje M. Kita w artykule Koncepcja oralności W.J. Onga a poglądy polskich badaczy języka mówionego, [w:] W kręgu języka polskiego, red. E. Jędrzejko, Wydawnictwo Uniwersytetu Śląskiego, Katowice 2001.

${ }^{41}$ Zob. „Język jest do tego stopnia oralny, że z wielu tysięcy języków - a możliwe, iż z dziesiątków tysięcy, jakimi mówiono w dziejach ludzkości, tylko około 106 na tyle związało się z pismem, że stworzyły literaturę, większość nie została nigdy zapisana. Spośród około 3000 języków, jakie są dzisiaj w użyciu, tylko około 78 ma literaturę", W.J. Ong, Oralność i piśmienność. Słowo poddane technologii, przekł. J. Japola, Redakcja Wydawnictw Katolickiego Uniwersytetu Lubelskiego, Lublin 1992, s. 27. 
czasom mediów, takich jak telefon, radio, telewizja oraz inne środki elektroniczne, których istnienie i funkcjonowanie wsparte jest pismem i drukiem ${ }^{42}$. Rozłączne historycznie, są powiązane rozmaitymi właściwościami:

Kultura cyfrowa zapoczątkowuje oralność wtórną. Ta pierwotna opierała się na mowie jako jedynym medium słowa, wtórna potęguje zaś cechy charakterystyczne dla kultury oralnej. Kładzie zatem nacisk na emocje, zaangażowanie i wzajemne relacje. Sposób wymiany informacji, dominujący w kulturze cyfrowej, ma charakter emocjonalny i ekspresyjny, a słowo jest nierozerwalnie związane z kontekstem jego użycia. Ważną rolę znów zaczyna odgrywać skupiona na teraźniejszości wspólnota. Oralność kultury mediów elektronicznych nie jest jednak wiernym odwzorowaniem oralności pierwotnej. Choć obie wykazują podobne tendencje, to różnią się przyczyną ich utrzymywania się $e^{43}$.

\section{Radio: słowo poddane technologii}

Czy zatem radio - jedna $\mathrm{z}$ jego najbardziej rozpowszechnionych metafor traktuje je jako „bęben plemienny” - funkcjonuje w ramach kultury oralnej w wersji wtórnej? Jak pisał Marshall McLuhan:

Radio działa na większość ludzi w sposób intymny, osobisty, nawiązując nić porozumienia między autorem i lektorem tekstu a słuchaczem [...]. W oddziaływaniu radia na podświadomość pobrzmiewają echa plemiennych rogów i starożytnych bębnów. Jest to podstawowa cecha tego przekaźnika, który potrafi i psychikę jednostki, i całe społeczeństwo zmienić w jeden wielki rezonator ${ }^{44}$.

\section{Uznaję w tej kwestii za zasadną ocenę Pleszkun-Olejniczakowej:}

[...] w tekście audialnym słowo funkcjonuje inaczej niż np. w tekście drukowanym, ale także - choć w inny sposób inaczej - niż w tekście audiowizualnym; i to

${ }^{42}$ Pismo wywiera na kulturę oralną wpływ nazwany przez Jacka Goody'ego lektooralnością, J. Goody, Mit, rytuat i oralność, przekł. O. Kaczmarek, Wydawnictwa Uniwersytetu Warszawskiego, Warszawa 2012, s. 75. Magdalena Szpunar proponuje wprowadzenie dystynkcji: „,...] proponuję, by nie tylko mówić za Ongiem o pierwotnej i wtórnej oralności, ale także o pierwotnej i wtórnej piśmienności. Pojęcie to rozumiem jako posługiwanie się pismem o zdeprecjonowanej roli, pismem służebnym wobec dominującego obrazu, które staje się wtórne w stosunku do treści ulegających wizualizowaniu", http://www.magdalenaszpunar.com/_publikacje/2014/4-Szpunar. pdf [dostęp: 26.06.2016].

${ }^{43} \mathrm{http}: / /$ www.kmt.uksw.edu.pl/media/pdf/kmt_2012_11_sitkowska.pdf [dostęp: 28.06.2016].

${ }^{44}$ Cyt. za: S. Jędrzejewski, dz. cyt., s. 155. 
w wielu aspektach. Nie myślę tu nawet o zaproponowanej przez Waltera Onga wtórnej oralności, choć samo to zjawisko obejmuje oczywiście także medium radiowe. W pewnych gatunkach radiowych - per analogiam - można by raczej mówić o swego rodzaju oralności pierwotnej, choć, rzecz jasna, ze swej natury „przekaz medialny [...] odznacza się [...] pośredniością [brak bezpośredniego, tj. twarzą w twarz, kontaktu między nadawcą medialnym a odbiorcą]", mimo iż w pewnych gatunkach radiowych [głównie w określonego typu audycjach popularnonaukowych] „wzrasta rola fatycznej funkcji języka tj. nawiązywania i podtrzymywania kontaktu" 45 .

W środowisku kultury oralnej komunikacja w świecie ludzi - poprzez słowo - łączy się nierozerwalnie z byciem we wspólnocie, ze wspólnym tu i teraz. To naturalny kontekst życiowy opowiadania przedpiśmiennego, a dziś potocznego ${ }^{46}$, i rozmowy. A są to dwie formy tekstowe, które żyją też w radiu, będącym medium więzi i bliskości ze słuchaczem [mimo braku wspólnego tu, mimo separacji przestrzennej]. Komunikacja oralna jest więc wspólnotowa, ma charakter dialogiczny, interaktywny, w kontraście do druku.

Tę właściwość wzmaga użycie przez dziennikarzy radiowych kategorii pierwszej osoby liczby mnogiej w funkcji tropu stylistycznego oraz form adresatywnych zmniejszających dystans, czyli właściwości języka potocznego, który zyskuje status odmiany językowej dominującej w wielu audycjach ${ }^{47}$. Tworzenie więzi przejawia się w językowych działaniach interaktywnych radiowców, takich jak rozmowy telefoniczne ze słuchaczami, wprowadzanie do audycji wypowiedzi słuchaczy nadchodzących drogą elektroniczną lub z użyciem tekstu SMS. Te strategie komunikacyjne wzmagają przywiązanie słuchacza do danej stacji, sprawiają, że zjawisko zappingu, charakterystyczne dla stylu odbioru programów telewizyjnych, w przypadku radia niemal nie działa.

Mówiący ma bezpośredni kontakt ze słuchaczami, którzy stają się w pewnym sensie współtwórcami jego opowieści. Ich reakcje wpływają bowiem na kształt przekazu. Także kontakt zapośredniczony radiowo skłania odbiorców do współtworzenia tekstu opowiadanego przez dziennikarza - dzieje się to poprzez autentyczne rozmowy telefoniczne in extenso, wyimki z wypowiedzi telefonicz-

${ }^{45}$ E. Pleszkun-Olejniczakowa, dz. cyt., s. 74-75. Szerzej zob. M. Steciąg, Oralność pierwotna $w$ wiadomościach radiowych, [w:] Wspótczesne odmiany języka narodowego, red. K. Michalewski, Wydawnictwo Uniwersytetu Łódzkiego, Łódź 2004, s. 238-246.

${ }^{46}$ Zob. K. Wyrwas, Opowiadanie potoczne w świetle genologii lingwistycznej, Wydawnictwo Uniwersytetu Śląskiego, Katowice 2014. Zob. też B. Lutostański, Wstęp do analizy narratologicznej stuchowisk radiowych, „Tekstualia” 2013, nr 1 (32): Literatura i radio, http://tekstualia.pl/ stara/index.php?DZIAL=teksty\&ID=790 [dostęp: 26.06.2016].

${ }^{47}$ D. Riesman, Tradycja oralna a stowo pisane, [w:] Antropologia stowa. Zagadnienia i wybór tekstów, opr. G. Godlewski, A. Mencwel, R. Sulima, Wydawnictwa Uniwersytetu Warszawskiego, Warszawa 2004, s. 398. 
nych, odczytane na antenie e-maile lub ich fragmenty. Widać to wyraźnie w toku dyżurów dziennikarskich czy programów śniadaniowych ${ }^{48}$.

Oralność jest nie tylko sposobem funkcjonowania tekstu, określana jest jako kategoria aksjologiczna, ściśle związana z aspektem moralno-etycznym, jest wykładnikiem światopoglądu określonych kultur, ich norm estetycznych i aksjologicznych. Oralność wyznaczona jest przez a) podmiotowość zanurzoną we wspólnotowości, b) spontaniczność, c) sytuacyjność, d) etologię. Tekst oralny jest - jak twierdzi P. Zumthor - różnorodny, kumulacyjny, wielobarwny, zróżnicowany niejednokrotnie aż do sprzeczności, stąd być może wynika wielość jego nazw, określany tekstem mówionym, potocznym, oralnym lub ustnym. Badacze języka wśród cech tekstu ustnego wymieniają najczęściej: dźwiękowość, gestyczność, sytuacyjność, dialogowość, przemijalność oraz spontaniczność 49 .

We współczesnej kulturze obrazu medium radiowe, a może środowisko radiowe, staje się przestrzenią rezydualną rozmowy. Toczy się ona na dwóch planach: to dialog sensu largo, co oznacza, że każdy komunikat radiowy jest przeznaczony dla audytorium radiowego, skierowany do niego, oraz rozmowy teksty reprezentujące jej różne odmiany gatunkowe - toczące się w studium czy konkretne rozmowy dziennikarzy ze słuchaczami zapośredniczone telefonicznie. Radio stanowi zatem środowisko dialogu, który przybiera czasem postać trylogu, czyli rozmowy prowadzonej przez trzy instancje, dziennikarza, jego rozmówcę $\mathrm{i}$ audytorium radiowe ${ }^{50}$.

Mówiąc o dialogu w radiu przejawiającym się w formie rozmowy, należy mieć na względzie, że rozmowa medialna stanowi iluzję prywatnej rozmowy face to face, o czym stanowi jej medialny kontekst życiowy. Technologia pozwala też na tworzenie rozmów preparowanych, składających się z fragmentu telefonicznej wypowiedzi słuchacza i komentarza radiowca, dodanego ex post, nie w toku realnej interakcji.

Elektralność / epoka elektroniczna zachwiała wielowiekową i utrwaloną opozycję oralności i piśmienności, co w przełożeniu na grunt językoznawczy oznacza binarną opozycję języka mówionego i pisanego. Wytworzyła się bowiem forma hybrydalna: język mówiono-pisany, występujący w takich formach generycznych, jak forum internetowe czy e-mail. Radio zmieniło też właściwości gatunków, które do jego przestrzeni medialnej trafiły ze sfery prywatnej.

\footnotetext{
${ }^{48}$ Zob. K. Albińska, Poranna audycja radiowa jako hybryda megagatunkowa (na podstawie wybranych programów z rozgłośni polskich i brytyjskich) [rozprawa doktorska napisana pod kierunkiem prof. Elżbiety Pleszkun-Olejniczakowej, Uniwersytet Łódzki, 2015].

${ }^{49} \mathrm{http} / / /$ biblioteka.teatrnn.pl/dlibra/Content/46023/oralnosc_w_kulturze.pdf [dostęp: 26.06.2016].

${ }^{50}$ Zob. Le trilogue, ed. C. Kerbrat-Orecchioni, Ch. Plantin, Presses Universitaires de Lyon, Lyon 1995.
} 
Rozmowa potoczna i rozmowa radiowa [czy szerzej: w mediach] to dwie różne odmiany tego megagatunku.

Właściwości oralności pierwotnej, które wskazał Ong, okażą się nośnym narzędziem dla opisu języka i zachowań językowo-komunikacyjnych w radiu, pozwolą też zinterpretować wiele zjawisk, zwłaszcza jeśli będziemy pamiętać, że

dzisiejszy przekaz radiowy - bogaty, zróżnicowany i polisemiczny - stanowi praktycznie nieograniczony konglomerat najróżniejszych realizacji językowych. To ważne stwierdzenie w kontekście badań językowej odmiany radiowej, zwłaszcza pragmatycznych funkcji używanych środków ${ }^{51}$.

\section{Zakończenie}

Ograniczenie radia do sfery fonicznej, realizacja Ongowskiej „wtórnej oralności”, powoduje swoiste ,zagęszczenie” środków wyrazu, by wyłącznie za pomocą odpowiednio wypowiadanych słów, muzyki i dźwięków, sytuowanych w rozmaitych kontekstach, oddać założoną istotę przekazu oraz przekonać słuchaczy do zawartego w komunikacie radiowym obrazu świata ${ }^{52}$.

To słowa Bogusława Skowronka, propagatora nowej, transdyscyplinarnie zorientowanej mediolingwistyki, która powinna dać nowy impuls badaniom nad komunikacją językową w radiu. W koncepcji oralności - pierwotnej i wtórnej, której środowiskiem jest m.in. radio jako medium dźwięku - tkwi duży potencjał intelektualny i metodologiczny mogący organizować studia nad językowym wymiarem radia. Ta koncepcja pozwala wyjść poza gramatyczny czy systemowy opis języka tego medium, a skoncentrować się na jego aspektach kognitywnych i pragmatycznych.

Oralność, wielka kategoria funkcjonująca w naukowej przestrzeni ponaddyscyplinowej, jest tym, co łączy w relacji synergicznej człowieka, kulturę i język oraz komunikację językową. Tym samym radio, czyli medium dźwięku, także językowego, stanowi przestrzeń komunikacyjną, która tworzy pole współpracy radioznawców i językoznawców.

\footnotetext{
${ }^{51}$ B. Skowronek, dz. cyt., s. 209.

52 Tamże, s. 208.
} 


\section{Bibliografia}

Aitchison J., Przedmowa, [w:] Atlas języków. Pochodzenie i rozwój języków świata, red. B. Comrie, S. Matthews, M. Polinsky, przekł. P. Gąsiorowski, Oficyna Wydawnicza Atena, Poznań 1998.

Albińska K., Poranna audycja radiowa jako hybryda megagatunkowa (na podstawie wybranych programów z rozglośni polskich i brytyjskich) [rozprawa doktorska napisana pod kierunkiem prof. Elżbiety Pleszkun-Olejniczakowej, Uniwersytet Łódzki, 2015].

Bajerowa I., Język ogólnopolski XX w., [w:] Wspótczesny język polski, red. J. Bartmiński, Wydawnictwo Uniwersytetu Marii Curie-Skłodowskiej, Lublin 2001, s. 23-48.

Briggs A., Burke P., Społeczna historia mediów: od Gutenberga do Internetu, przekł. J. Jedliński, Wydawnictwo Naukowe PWN, Warszawa 2010.

Bugajski M., Język a przestrzenie wizualne i akustyczne, [w:] A. Janiak, W. Krzemińska, A. Wojtasik-Tokarz, Przestrzenie wizualne i akustyczne człowieka. Antropologia audiowizualna jako przedmiot i metoda badań, Wydawnictwo Naukowe Dolnośląskiej Szkoły Wyższej Edukacji TWP, Wrocław 2007, s. 65-73.

Cisza i milczenie. Społeczno-kulturowe mechanizmy kreowania emocji, red. B. Syroka, K. Marcehl, seria Antropologia Emocji, t. 1, Oficyna Wydawnicza Arboretum, Wrocław 2010.

Fry D., Homo Loquens: Man as a Talking Animal, Cambridge University Press, Cambridge 1977.

Gadżety popkultury. Społeczne życie przedmiotów, red. W. Godzic, M. Żakowski, Wydawnictwa Naukowe i Profesjonalne, Warszawa 2007.

Goody J., Mit, rytuat i oralność, przekł. O. Kaczmarek, Wydawnictwa Uniwersytetu Warszawskiego, Warszawa 2012.

Inny słownik języka polskiego PWN, t. 2, red. M. Bańko, Wydawnictwo Naukowe PWN, Warszawa 2000 .

Jabłoński H., Opinia, parlament, prasa. Wstęp do badań roli opinii publicznej w epoce rozkwitu kapitalizmu, Zakład Narodowy im. Ossolińskich, Wrocław 1985.

Japola J., Tekst czy głos? Waltera J. Onga antropologia literatury, Redakcja Wydawnictw Katolickiego Uniwersytetu Lubelskiego, Lublin 1998.

Jędrzejewski S., Radio, [w:] Stownik wiedzy o mediach, red. E. Chudziński, Wydawnictwo Szkolne PWN, Warszawa, ParkEdukacja Bielsko-Biała 2007, s. 154-172.

Jędrzejewski S., Radio. Narodziny - ewolucja-perspektywy, [w:] Dziennikarstwo i świat mediów. Nowa edycja, red. Z. Bauer, E. Chudziński, Towarzystwo Autorów i Wydawców Prac Naukowych Universitas, Kraków 2010, s. 115-126.

Kita M., Dyskurs radiowy, [w:] Style wspótczesnej polszczyzny. Przewodnik po stylistyce polskiej, red. E. Malinowska, J. Nocoń, U. Żydek-Bednarczuk, Towarzystwo Autorów i Wydawców Prac Naukowych Universitas, Kraków 2013, s. 313-346.

Kita M., Koncepcja oralności W.J. Onga a poglady polskich badaczy języka mówionego, [w:] $W$ kręgu języka polskiego, red. E. Jędrzejko, Wydawnictwo Uniwersytetu Śląskiego, Katowice 2001, s. 116-130.

Kwiatkowski M.J., Narodziny Polskiego Radia: radiofonia w Polsce w latach 1918-1929, Państwowe Wydawnictwo Naukowe, Warszawa 1972.

Le trilogue, ed. C. Kerbrat-Orecchioni, Ch. Plantin, Presses Universitaires de Lyon, Lyon 1995.

Losiak R., Muzyka w przestrzeni publicznej miasta. Z badań nad pejzażem dźwiękowym Wrocławia, [w:] Dźwięk jako przedmiot badań interdyscyplinarnych. Prace Komisji Krajobrazu Kulturowego, t. 11, red. S. Bernat, Instytut Nauk o Ziemi Uniwersytet Marii Curie-Skłodowskiej: Komisja Krajobrazu Kulturowego Polskiego Towarzystwa Geograficznego, Lublin 2008, s. 253-264. 
McLuhan M., Wybór pism, przekł. K. Jakubowicz, Wydawnictwa Artystyczne i Filmowe, Warszawa 1975 .

McLuhan M., Zrozumieć media. Przedłużenia człowieka, przekł. N. Szczucka, Wydawnictwa Naukowo-Techniczne, Warszawa 2004.

Misiak T., Estetyczne konteksty audiosfery, Wyższa Szkoła Nauk Humanistycznych i Dziennikarstwa, Poznań 2009.

Moorhouse R., Stolica Hitlera. Życie i śmierć w wojennym Berlinie, przekł. J. Wąsiński, Społeczny Instytut Wydawniczy Znak, Kraków 2011.

Obirek S., Uskrzydlony umyst. Antropologia stowa Waltera Onga, Wydawnictwa Uniwersytetu Warszawskiego, Warszawa 2010.

Ong W.J., Oralność i piśmienność. Słowo poddane technologii, przekł. J. Japola, Redakcja Wydawnictw Katolickiego Uniwersytetu Lubelskiego, Lublin 1992.

Pleszkun-Olejniczakowa E., Jakjest zrobione stuchowisko? O morfologii i znaczeniu, o kreacji i zna$k u$, [w:] E. Pleszkun-Olejniczakowa, J. Bachura, A. Pawlik, Dwa teatry. Studia z zakresu teorii i interpretacji sztuki stuchowiskowej, Wydawnictwo Adam Marszałek, Toruń 2011, s. 59-140.

Radio i społeczeństwo, red. G. Stachyra, E. Pawlak-Hejno, Wydawnictwo Uniwersytetu Marii Curie-Skłodowskiej, Lublin 2011.

Riesman D., Tradycja oralna a stowo pisane, [w:] Antropologia stowa. Zagadnienia $i$ wybór tekstów, opr. G. Godlewski, A. Mencwel, R. Sulima, Wydawnictwa Uniwersytetu Warszawskiego, Warszawa 2004, s. 395-401.

Rokoszowa J., Język, czas, milczenie, Wydawnictwo Oddziału Polskiej Akademii Nauk, Warszawa 1999.

Semantyka milczenia: zbiór studiów, red. K. Handke, Instytut Slawistyki Polskiej Akademii Nauk, Katedra Teorii Muzyki Akademii Muzycznej im. Fryderyka Chopina, Slawistyczny Ośrodek Wydawniczy przy Instytucie Slawistyki PAN, Warszawa 1999.

Skowronek B., Mediolingwistyka. Wprowadzenie, Wydawnictwo Naukowe Uniwersytetu Pedagogicznego, Kraków 2013.

Stachyra G., Radiomorfozy. Profilowanie przekazu na przykladzie radia Hair Trendy, [w:] Radio $w$ dobie nowych mediów, red. U. Doliwa, Wydawnictwo Uniwersytetu Warmińsko-Mazurskiego, Olsztyn 2014, s. 115-131.

Steciąg M., Oralność pierwotna w wiadomościach radiowych, [w:] Współczesne odmiany języka narodowego, red. K. Michalewski, Wydawnictwo Uniwersytetu Łódzkiego, Łódź 2004, s. $238-246$.

Wyrwas K., Opowiadanie potoczne w świetle genologii lingwistycznej, Wydawnictwo Uniwersytetu Śląskiego, Katowice 2014.

\section{Netografia}

http://alehistoria.blox.pl/2012/05/BRUNATNE-CZASY-RADIA.html [dostęp: 26.06.2018].

http://biblioteka.teatrnn.pl/dlibra/Content/46023/oralnosc_w_kulturze.pdf [dostęp: 26.06.2016].

http://naukawpolsce.pap.pl/aktualnosci/news,398768,komora-bezechowa-agh-jak-nowa.html [dostęp: 26.06.2016].

http://sjp.pwn.pl/sjp/cisza;2449472.html [dostęp: 26.06.2016].

http://tech.wp.pl/kat,1009779,title,Upiorna-komora-ktora-doprowadza-do-szalenstwa-Ile-bys-wytrzymal,wid,14391366,wiadomosc.html?ticaid=116f18 [dostęp: 26.06.2016]. 
http://waldisaren.bloog.pl/id,347610641,title,Dzwiek,index.html?smoybbtticaid=616e40 [dostęp: 26.06.2016].

http://www.bu.kul.pl/walter-j-ong-jr-sj-1912-2003-sylwetka-i-publikacje,art_11256.html [dostęp: 26.06.2016].

http://www.hifi.pl/slownik/komora-bezechowa.php [dostęp: 26.06.2016].

http://www.kmt.uksw.edu.pl/media/pdf/kmt_2012_11_sitkowska.pdf [dostęp: 28.06.2016].

http://www.lat.agh.edu.pl/pomieszczenia/komora-bezechowa/ [dostęp: 26.06.2016].

http://www.magdalenaszpunar.com/_publikacje/2014/4-Szpunar.pdf [dostęp: 26.06.2016].

http://www.media-ecology.org/publications/MEA_proceedings/v6/berg.pdf [dostęp: 26.06.2016].

http://www.polskieradio.pl/39/156/Artykul/1085552,Guglielmo-Marconi-i-poczatki-radia [dostęp: 26.06.2016].

http://www.polskieradio.pl/39/156/Artykul/713951,Wojna-swiatow-tylko-Clint-Eastwood-nie-uwierzyl-w-te-historie [dostęp: 26.06.2016].

http://www.polskieradio.pl/8/2222/Artykul/988121,Kultura-oralna-\%E2\%80\%93-slowo-zwiazane-z-cialem [dostęp: 26.06.2016].

http://www.polskieradio.pl/9/398/Artykul/231470,Co-to-jest-radio [dostęp: 26.06.2016].

http://www.tygodnikprzeglad.pl/radiowe-imperium-goebbelsa/ [dostęp: 26.06.2016].

https://horyzonty.ignatianum.edu.pl/index.php/HW/article/view/314/281 [dostęp: 26.06.2016].

https://pl.wikipedia.org/wiki/Polskie_Radio_Program_IV [dostęp: 26.06.2016].

https://pl.wikiquote.org/wiki/Radio [dostęp: 26.06.2016].

https://www.youtube.com/watch?v=Xs0K4ApW14g [dostęp: 26.06.2016].

Lutostański B., Wstęp do analizy narratologicznej stuchowisk radiowych, „Tekstualia” 2013, nr 1

(32): Literatura i radio, http://tekstualia.pl/stara/index.php?DZIAL=teksty\&ID=790 [dostęp: 26.06.2016].

\section{Małgorzata Kita}

\section{Radio and orality - from the linguistic perspective}

\section{(Summary)}

Radio as a sound medium, as elaborated in the typical definition of it, constitutes an integral component of the human audiosphere. Human culture is, at source, oral in nature. Orality, a huge category that operates outside of individual academic disciplines, is that which links in a synergy the human being, culture and language, as well as linguistic communication. The author, starting from these ruminations, shows how the theory of orality created by Walter J. Ong may constitute a stable instrument for the description of language and linguistic-communicative behaviours on radio, and enable us to interpret numerous phenomena of radio discourse.

Keywords: orality, language in the media, media communication. 